\title{
O PROCESSO DE PROJETO DE INTERIORES E O USO DA ERGONOMIA NA PRÁTICA SEGUNDO A VISÃO DE PROFISSIONAIS E USUÁRIOS
}

\section{THE PROCESS OF INTERIOR DESIGN AND THE USE OF HUMAN FACTORS IN PRACTICE, ACCORDING THE POINT OF VIEW OF PROFESSIONALS AND USERS}

\author{
Gilberto Rangel de Oliveira, D.Sc. ${ }^{1}$ \\ Claudia Renata Mont'Alvão, D.Sc. ${ }^{2}$ \\ (1) Pontifícia Universidade Católica - PUC-Rio \\ e-mail: grangeldesign@gmail.com \\ (2) Pontifícia Universidade Católica - PUC-Rio \\ e-mail:cmontalvao@puc-rio.br
}

Projeto de interiores, metodologia de projeto, usuários

O método projetual aplicado na atividade de design de interiores (ou projeto de interiores) apresenta peculiaridades próprias do profissional em ação. No presente trabalho realizou-se pesquisa descritiva junto aos profissionais e os usuários que contrataram esta prestação de serviço, a fim de compreender como ocorre esse processo e como a ergonomia costuma ser aplicada, suas consequências e resultados.

Interior design, project methodology, users

The design method applied in the activity of interior design (or interior design) presents peculiarities of the professional in action. A descriptive research was carried out with the professionals and the users who contracted this service, in order to understand how this process occurs and how ergonomics is usually applied, consequences and results.

\section{Introdução}

Projetar é uma ação artificial e complexa. O projeto requer uma atuação criativa, acúmulo de informação, conhecimento e alguma experiência. Enfrenta desafios complicados, como definir com precisão os reais problemas dos usuários e planejar possíveis soluções, considerando níveis de necessidades a serem atendidos. O projeto não é uma exclusividade dos profissionais do campo das criações bi e tridimensional, ele costuma ser exercido nos mais variados campos do conhecimento, principalmente por arquitetos, designers e engenheiros. Neste artigo faz-se um recorte para tratar dos aspectos do processo de projeto relacionados à atividade de design de interiores no segmento residencial. Trata-se de uma atividade com considerável reconhecimento na sociedade, mas que ainda passa por processo de afirmação, mesmo considerando o elevado número de profissionais atuando no mercado.

No Brasil e em alguns lugares do mundo (com algumas variações) ${ }^{1}$ o exercício da atividade de design de interiores vem sendo praticado invariavelmente por arquitetos, designers e designers de interiores. Como veremos no transcorrer do trabalho, a atividade é predominantemente exercida por profissionais com formação em arquitetura e urbanismo, os quais contam a seu favor com o peso da tradição histórica do exercício da profissão e o amparo legal de estruturas regulamentadoras.

Por outro lado, é cada vez maior o número de profissionais que atuam nesse mercado com

\footnotetext{
1 Extraído de: International Federation of Interior Architects / Designers and International Design Aliance - IFI-IDA. $<$ http://www.ifiworld.org/\#About IFI $>$. Acesso em: 20.jan.2016.
} 
formação em design de interiores e até em desenho industrial (em ambas as formações, bacharelado ou tecnólogo) - essa última em menor número. Sabe-se também que em virtude do crescimento econômico e do interesse por ambientes corretamente planejados, é crescente a demanda dessa atividade por parte de usuários que costumam buscar conforto, funcionalidade e boa estética nos ambientes.

Através de pesquisa descritiva investigou-se se os profissionais de $\mathrm{DI}^{2}$, durante o desenvolvimento de suas atividades, fazem uso de métodos, quais ferramentas utilizam, com que regularidade e as consequências disso para o desenvolvimento do projeto. Pretende-se relatar como os profissionais tratam as necessidades dos usuários, quais aspectos de ergonomia conhecem e de que forma aplicam e, ainda, como estes aspectos influenciam para os usuários/ clientes. Por fim, buscou-se conhecer qual o ponto de vista dos usuários que contratam esse tipo de serviço e se os métodos _ técnicas adotados conseguem atender às expectativas destes.

Acredita-se que os conhecimentos de ergonomia, quando agregados à prática projetual, a partir da acepção de que a ergonomia é aplicada para melhorar o projeto e o funcionamento de sistemas, equipamentos e o ambiente com os quais as pessoas interagem, podem levar à geração de melhores resultados.

\subsection{Uma atividade com diversos métodos}

Naturalmente, por ser uma atividade praticada por profissionais que podem vir de três formações diferentes, não é exatamente um "fator surpresa" que cada profissional, à sua maneira, desenvolva suas atividades baseado em métodos de projeto aos quais tiveram acesso na academia e/ou em seu modus faciendi. Ou seja, os profissionais, de posse do conhecimento que adquirem durante sua formação acadêmica, aplicam (ou tentam aplicar) os processos de projeto (métodos) conforme seu entendimento na busca da solução projetual pretendida.

\footnotetext{
${ }^{2}$ Neste trabalho será utilizada a expressão "profissionais de DI" para designar os profissionais de arquitetura e urbanismo, design industrial e design de interiores.
}

O ponto de partida para a discussão do processo de trabalho dos profissionais que exercem a atividade de design de interiores é o aspecto do método de projeto. De maneira simples, o método traduz-se como procedimento, técnica ou meio para se atingir um objetivo. Desta forma, cada atividade possui seu próprio entendimento para o método de projeto. $\mathrm{Na}$ arquitetura, o método "estabelece princípios ou normas de ação aplicáveis na atividade de elaboração de projetos". O arquiteto, por sua vez, faz uso do projeto no sentido de atender às expectativas do cliente, considerando determinados parâmetros. Silva (1998, p.32 e 38) explica que o projeto arquitetônico "é uma proposta de solução para um particular problema de organização do entorno humano, através de uma determinada forma construível, bem como a descrição desta forma e as prescrições para sua execução".

No campo do design, pela sua natureza interdisciplinar característica, "seus métodos são de origem diferenciada, dependendo do problema tratado e do corpo teórico a que se relaciona o método de projeto". A abordagem científica dos estudos dos métodos de projeto em design ocorre desde aproximadamente a década de 50, quando o design rompeu alguns vínculos importantes que mantinha ainda com a tradição artística na produção de artefatos, no sentido de colaborar com as novas exigências do campo. (Cipiniuk, in: Coelho (org.) 2006, p. 32).

A atividade de design de interiores (como é entendida atualmente) estabeleceu-se em meados do século XVIII, construindo um elo de interseção entre a arquitetura e o design, conforme alguns autores defendem. A origem da própria atividade está ligada à formação em arquitetura, afinal, a grande maioria dos primeiros designers de interiores era formada por arquitetos. Não diferente do que acontece na arquitetura, o processo de projeto de interiores $^{3}$ é traduzido como uma sequência de fases

\footnotetext{
${ }^{3}$ Neste estudo será adotado o termo projeto de interiores para designar o produto resultado da elaboração intelectual de criação da atividade de design de interiores. Sendo assim, quando usarmos o termo design de interiores estará sendo aclamada a atividade que é responsável por gerar projetos de interiores.
} 
que se inicia com a elaboração do programa de necessidades, passando pelo desenvolvimento de ideias e a elaboração do projeto executivo.

\subsection{Desafios da atividade de design de interiores}

A atividade de design de interiores, pela própria origem e formação, apresenta características híbridas, que irão desenhar uma profissão interdisciplinar e multidisciplinar. A interdisciplinaridade está caracterizada quando o conhecimento atravessa diferentes disciplinas no ensino e, consequentemente, a prática da atividade. A multidisciplinaridade, por sua vez, assemelha-se à primeira, contudo o fenômeno ocorre simultaneamente. A atividade projetual dos profissionais de D.I. cruza diferentes práticas profissionais e conhecimentos teóricos de diferentes naturezas.

Naturalmente, cada profissional - dependendo de sua formação - adotará as práticas absorvidas durante sua formação profissional. Assim, o arquiteto adotará o método de trabalho que aprendeu durante seu curso de arquitetura; o designer tentará empregar um dos métodos de projeto que conheceu quando aluno e, naturalmente, tentará aplicar (ou adaptar) o conhecimento às necessidades próprias da atividade; já o designer de interiores colocará em prática as fases do método de projeto comumente ensinado nas escolas brasileiras. Não se pode deixar de mencionar que a práxis é um fator determinante para o uso desta ou daquela metodologia e de possíveis adequações.

Ainda considerando a interdisciplinaridade que caracteriza a profissão de designer de interiores, traz-se a relevância dos conhecimentos dos profissionais de projeto acerca da disciplina científica ergonomia. Sabe-se que este conhecimento possui princípios sólidos que visam atender às necessidades dos usuários, considerando "aspectos de saúde, segurança, satisfação e eficiência", conforme assegura Iida (2005, p. 3). Considerando esse enunciado, acredita-se que os princípios da Ergonomia do Ambiente Construído (EAC) - viés mais recente da própria ergonomia constituem-se como relevante incremento para contribuir para a plena satisfação dos usuários no ambiente construído. Moraes (2004, apud Buti, 1998, p. 68) acrescenta que a EAC deve "ocupar-se de quem usará, que coisa será usada, mas principalmente onde virá a ser usada. O onde é o ambiente de destinação que deve ser analisado como lugar físico e sociocultural que condiciona a interação entre o homem e o objeto".

\section{A Pesquisa}

As estratégias de inquirição utilizadas na pesquisa foram elaboradas através de cuidadoso percurso metodológico de investigação, realizado por meio de entrevistas, elaboração de questionário, pré-teste e aplicação do questionário definitivo junto a profissionais e usuários. Estão detalhadas nesta seção as etapas da aplicação da inquirição, os instrumentos (técnicas) utilizados, os critérios de participação na inquirição e a forma de aplicação de cada técnica. Todos os inquiridos assinaram o termo de consentimento de coleta de dados, padrão PUCRio.

Foram estabelecidas três etapas distintas durante o desenvolvimento da pesquisa: Etapa Ipreliminares da inquirição (entrevista não estruturada); Etapa II - inquirição com os profissionais de D.I (pré-teste e questionário definitivo); Etapa III - inquirição com os usuários.

\subsection{Etapa I - entrevista não estruturada}

As entrevistas ocorreram no mês de janeiro de 2015 e foram realizadas na residência e/ou no escritório dos profissionais. Por tratar-se de uma entrevista não estruturada, utilizou-se gravador digital como forma de registro da conversa. "As entrevistas menos estruturadas desenvolvem-se de forma mais espontânea, sem que estejam sujeitas a um modelo apriorístico de interrogação" (Moraes \& Mont'Alvão, 2012, p. 70).

Para realização da entrevista não estruturada partiuse de uma pergunta aberta, ampla, e então o profissional ficou livre para verbalizar as informações desejadas. Levantou-se a seguinte questão com os profissionais selecionados para a 
entrevista: Qual seu ponto de partida para desenvolvimento de um projeto de design de interiores? Na sequência, a entrevista foi conduzida através de tópicos pré-estabelecidos.

Essa questão foi aplicada a cinco profissionais (três arquitetos urbanistas e dois designers de interiores, nível tecnólogo) que exercem a atividade de design de interiores na cidade do Rio de Janeiro - capital, com ênfase em projetos residenciais. Todos possuem experiência profissional acima de cinco anos de atuação no mercado.

Conforme explicação de Marconi \& Lakatos (2002, p. 94) sobre a entrevista não estruturada, as autoras orientam: "as perguntas são abertas e podem ser respondidas dentro de uma conversação informal", possibilitando uma conversa ampla, e que algumas vezes se faz necessário trazer o entrevistado para o foco da questão.

Os profissionais entrevistados contribuíram de forma significativa para elaboração do questionário, esclarecendo sobre qual seu processo (individual) no desenvolvimento do projeto de interiores ${ }^{4}$. Sendo assim, foi possível planejar o questionário subdividindo-o em 6 (seis) fases ou tópicos: fase inicial do projeto; investigação de necessidades; avaliação da satisfação do usuário sobre a proposta; questões de ergonomia e usabilidade.

\subsection{Etapa II - inquirição ${ }^{5}$, o questionário}

Nesta segunda etapa foi realizada a inquirição com os profissionais de D.I. O objetivo desta etapa era conhecer e interpretar o processo projetual praticado por esses profissionais junto aos usuários (clientes). Nesse sentido, conforme entendimento da pesquisa

\footnotetext{
${ }^{4}$ Neste estudo será adotado o termo projeto de interiores para designar o produto resultado da elaboração intelectual de criação da atividade de design de interiores. Sendo assim, quando usarmos o termo design de interiores estará sendo aclamada a atividade que é responsável por gerar projetos de interiores.

${ }^{5}$ No contexto da pesquisa científica o termo inquirição "implica a busca metódica de informações e a quantificação, sempre que possível, dos resultados" (Moraes \& Mont'alvão, 2012, p. 69).
}

descritiva, interessa-nos descobrir e observar fenômenos, descrevê-los, classificá-los e interpretálos.

O conteúdo do questionário ${ }^{6}$ nasceu a partir das entrevistas realizadas com os profissionais de D.I. e de reflexões do autor, fundamentado nos enunciados teóricos do trabalho. Moraes \& Mont'Alvão (2012, p. 74) são taxativas em afirmar que "um bom questionário com perguntas fechadas deve ser precedido da entrevista pautada. Deste modo, o pesquisador familiariza-se com a temática e suas implicações e conhece os discursos e os limites dos futuros questionados".

Como toda coleta de dados, o questionário apresenta uma série de vantagens e desvantagens. Marconi \& Lakatos (2002, p. 98-99) fazem um minucioso relato sobre os principais benefícios e os inconvenientes do uso dessa técnica de pesquisa. Para este estudo, as principais vantagens na utilização desta ferramenta foram: economizou-se tempo; atingiu-se maior número de pessoas simultaneamente; abrangeu-se uma área geográfica mais ampla; obteve-se respostas mais rápidas e mais precisas; creditou-se maior liberdade para respostas, em razão do anonimato; não houve risco de distorção das questões, devido a não influência do pesquisador.

As maiores desvantagens sobre o uso da técnica utilizada na pesquisa foram: dificuldade no retorno dos questionários respondidos; alguns documentos apenas parcialmente respondidos; a devolução tardia, que prejudicou um pouco o calendário de elaboração do trabalho; e o desconhecimento das circunstâncias nas quais o documento foi respondido.

\subsubsection{Teste piloto-pré-teste}

Antes de aplicar o documento definitivo, faz-se

\footnotetext{
${ }^{6}$ Marconi \& Lakatos (2002) defendem o questionário como instrumento de pesquisa por destacar-se principalmente a averiguação de fatos e descoberta de planos de ação. Sendo assim, buscou-se descobrir: "O que as pessoas pensam ou acreditam que os fatos sejam" e "por meio das definições individuais dadas, qual a conduta adequada em determinadas situações, a fim de prever qual seria a sua".
} 
necessário um teste do modelo elaborado junto a uma pequena população, com características semelhantes ao público-alvo. O questionário - préteste para os profissionais de D.I foi aplicado junto a 10 (dez) profissionais da área de design de interiores, com experiência de mercado acima de cinco anos. $\mathrm{O}$ grupo foi formado por 6 (seis) arquitetos, 2 (dois) designers e 2 (dois) designers de interiores, profissionais da cidade do Rio de Janeiro.

Marconi \& Lakatos (2002, p. 100) ensinam que o objetivo é testar o documento elaborado, verificando possíveis falhas existentes, tais como: inconsistência ou complexidade das questões; ambiguidade ou linguagem inacessível; perguntas desnecessárias ou que causem embaraço ao inquirido; e ainda se as questões obedecem a determinada ordem sequencial ou até se o número de questões está em excesso.

\subsubsection{Aplicação do questionário definitivo com os profissionais de DI.}

No período de 14 de maio a 01 de julho de 2015 aplicou-se o questionário definitivo junto aos profissionais de DI, que representarão a amostra da pesquisa. $\mathrm{O}$ número total de questionários válidos foi de 85 (oitenta e cinco) respondentes. A plataforma de aplicação das perguntas foi o software Evalandgo. O número total de questões do instrumento de pesquisa foi 19, distribuídas em seis tópicos: fase inicial do projeto; investigação de necessidades; elaboração de propostas; apresentação de projeto; avaliação de satisfação dos usuários; e ergonomia e usabilidade.

As perguntas, em sua maioria, foram do tipo fechadas, com respostas de múltipla escolha. Em algumas perguntas era possível marcar mais de uma resposta; em outras apenas uma.

O perfil estabelecido, proposto para a investigação, preconizava os seguintes critérios para participar da inquirição:

- possuir formação acadêmica nas áreas de arquitetura, ou design (preferencialmente habilitação produto) ou design de interiores;

- atuar profissionalmente no mercado de design de interiores com tempo superior a um ano;
- haver realizado projetos de design de interiores no segmento residencial recentemente;

- residir e/ou atuar em qualquer município do território nacional.

As fontes de acesso ao público-alvo foram as seguintes: profissionais participantes do evento Casa Cor (maior mostra nacional de decoração do país) na cidade de São Paulo (edição 2014 e 2015) e na cidade do Rio de Janeiro (edição 2014); mailing da loja de móveis planejados Florense Ipanema - Rio de Janeiro; contatos realizados com presidentes da ABD - Associação Brasileira de Design de Interiores, nacional e regionais de SP, DF e RS; contatos pessoais com profissionais da área de design de interiores, construídos ao longo da vida profissional do pesquisador.

Ao final de quase dois meses de trabalho, aproximadamente 400 (quatrocentos) e-mails haviam sido enviados. A plataforma do software Evalandgo registrou 115 (cento e quinze) questionários respondidos. No final foi necessário realizar um corte de $26 \%$ (vinte e seis por cento) do total dos questionários respondidos.

\subsection{Etapa III - inquirição com os usuários}

Esta etapa tratou da inquirição com 32 usuários que contrataram os serviços dos profissionais de D.I. e implantaram seus projetos. Os critérios adotados para confecção da amostra foram:

- ter contratado os serviços de profissionais de D.I. para execução de projeto de interiores para sua residência;

- ter implantado o projeto, ou seja, o usuário deveria ter passado por todas as etapas do processo de projeto: contratação, proposta, aprovação e implantação;

- o usuário deverá ter realizado no mínimo o projeto de dois ambientes da residência, para uma avaliação mais completa e abrangente;

- o projeto de interiores fora realizado e implantado há pelo menos 36 meses ou menos.

Definido o perfil do inquirido para a pesquisa surgiu um problema. Como chegar a este tipo tão específico de usuário? Trata-se de um desafio, pois 
além dos pré-requisitos estabelecidos para seleção da amostra da população, pretende-se inquirir pessoas sobre uma determinada prestação de serviços e implantação do projeto - o que leva o entrevistado a dispor-se a tratar de assuntos próximos do nível pessoal. Explica-se: em geral, o projeto de interiores exige uma participação intensa e contínua de convivência com o usuário (cliente) e o cotidiano da residência. É natural que alguns possíveis usuários, embora adequados para a pesquisa, não se sintam à vontade para tratar sobre, ou não queiram revelar determinados aspectos da relação cliente - profissional. Este tipo de "entrave" para a pesquisa ocorre justamente por conta de laços de amizade que em geral se formam (ou deixam de existir) numa relação entre usuários (clientes) e os profissionais de D.I.

Considerando-se os aspectos citados inicialmente, pensou-se em solicitar auxílio aos profissionais de D.I. que haviam prontamente atendido aos pedidos de participação na fase II da pesquisa, através do questionário. Depois observou-se que isto poderia causar possíveis distorções, pois o pesquisador não poderia ter controle sobre a amostra (a indicação partiria dos próprios profissionais de D.I.), o que poderia levar a uma amostra tendenciosa por questões óbvias - temeu-se que as indicações fossem apenas de projetos muito bem-sucedidos e clientes com ligação muito próxima com os profissionais, e naturalmente satisfeitos com seu trabalho. Isto certamente poderia pôr em risco a investigação científica da pesquisa.

Resolveu-se o problema recorrendo-se a algumas fontes em que era possível assegurar-se de uma amostra que atendesse aos pré-requisitos estabelecidos. Sendo assim, fez-se solicitações através das redes sociais (principalmente através da rede social Facebook) a alguns profissionais da área acadêmica, que colaboraram indicando amigos ou conhecidos que atendiam aos critérios da pesquisa, e ainda clientes que realizaram, durante a fase de execução do seu projeto, a compra dos armários na fábrica gaúcha de móveis planejados Florense.

O pré-teste do questionário foi aplicado em 5 (cinco) usuários, que preenchiam totalmente os critérios pré-estabelecidos da amostra. Foi realizado nos meses de junho e julho de 2015, na cidade do Rio de Janeiro, capital.

A ferramenta foi aplicada exatamente como se planejou executar a inquirição definitiva: depois da anuência do convidado à pesquisa, formalizava-se o processo através de $e$-mail, o qual fora enviado contendo informações gerais sobre a pesquisa e convite para acessar o termo de consentimento, padrão PUC -Rio. No mesmo e-mail, seguiram algumas explicações sobre a pesquisa e o link de acesso ao software Evalandgo. Ao clicar no link, automaticamente o questionário era aberto, e depois de respondido um texto de agradecimento era apresentado para o entrevistado e as informações ficavam gravadas no banco de dados da plataforma. $O$ processo era encerrado.

Pretendia-se levantar de 30 (trinta) a 40 (quarenta) questionários respondidos para esta etapa da pesquisa. No dia 14 de setembro a plataforma do software Evalandgo registrou 37 (trinta e sete) questionários respondidos. Diferentemente do questionário aplicado aos profissionais de D.I., os perfis dos respondentes estavam todos totalmente corretos, pois foi realizada uma apuração mais profunda e individualizada para participação do entrevistado na pesquisa - principalmente devido aos critérios de participação pré-estabelecidos.

Do total de pesquisas respondidas, 05 (cinco) foram eliminados pelos seguintes motivos: questionário respondido de forma incompleta e questionário com o nome do entrevistado repetido. Fazendo-se o corte necessário, fechou-se o trabalho com 32 (trinta e dois) respondentes. A pesquisa definitiva com os usuários ocorreu entre os dias 14 de julho e 14 de setembro de 2015, na cidade do Rio de Janeiro, capital.

\section{Resultados}

\subsection{Considerações sobre o questionário aplicado com os profissionais de D.I.}

De acordo com os dados obtidos na pesquisa foi possível traçar um esboço do perfil dos profissionais 
que atuam no mercado brasileiro de design de interiores. Conforme inquirição realizada em números absolutos: 67 respondentes são do sexo feminino e 18 do sexo masculino; 52 possuem formação em arquitetura e urbanismo e 26 são designers e/ou designers de interiores; 60 respondentes exercem profissionalmente suas atividades há mais de 10 anos; 39 respondentes trabalham no Rio de Janeiro; 17 trabalham em Minas Gerais e os demais 29 respondentes atuam entre as regiões sul, sudeste, nordeste e centro-oeste; e, por fim, 57 respondentes afirmaram que fizeram algum curso de formação complementar (tipo latosensu - especialização) após a graduação e 28 não fizeram nenhum curso complementar.

A inquirição revelou que cerca de $60 \%$ dos profissionais disseram praticar (de alguma forma) as três etapas básicas de um processo projetual, seja através de etapas sistemáticas organizadas ou quase de forma "intuitiva". De acordo com os dados levantados na pesquisa, há indícios de que a atividade, de uma maneira geral, costuma atravessar as etapas de compreensão do problema, geração de alternativas e definição da alternativa escolhida (etapas comuns nas atividades de projeto). Pode-se considerar com esses resultados que os profissionais de D.I. possuem consciência das etapas empregadas e compreendem (de alguma forma) o processo metodológico sequencial.

A etapa inicial do desenvolvimento do projeto de interiores é em geral implementada utilizando-se as ferramentas tradicionais de pesquisas em ciências sociais, como entrevista aberta e questionário. A inquirição revelou que $90 \%$ dos profissionais inquiridos utilizam as seguintes técnicas na fase inicial de investigação de necessidades: (1) entrevista com o cliente; (2) realiza medição no local; (3) visita o local que o trabalho será realizado; (4) fotografa o local em que o trabalho será realizado. Um percentual significativo, de $16 \%$, apontou para a opção (5), "aplicam o questionário com o cliente", e o mesmo percentual de profissionais afirmou que utiliza outras técnicas.

Investigou-se, também, como é tratada a identificação de necessidades, quando na etapa inicial não se atende totalmente à expectativa do cliente (usuário). A maior dificuldade em tratar desse assunto possivelmente reside no fato de cada projeto ser um projeto, cada cliente, um cliente. Provavelmente por isso a maior parte das respostas apontadas pelos profissionais direcionou para soluções que lançam mão de recursos visuais, como esboços, fotos de revistas e imagens virtuais, a fim de sanar as dúvidas que pairam sobre a identificação das necessidades dos usuários. Identificou-se que $80 \%$ fazem uso de esboços, croquis ou imagens que contribuem com sua argumentação; $71 \%$ apresentam referências e também tentam conversar novamente com o cliente para aprofundar a questão; e, por fim, $55 \%$ disseram que apresentam trabalhos anteriormente realizados para tratar das dificuldades na identificação das necessidades do cliente.

Os profissionais também foram arguidos sobre como realizam os registros levantados sobre a investigação das necessidades apontadas pelos clientes durante a fase inicial do projeto. Conforme foi identificado na pesquisa, 92\% "faz anotações" para registrar as informações sobre as necessidades identificadas; $72 \%$ realizam "desenhos ou anotações no esboço do projeto". E um número significativo de inquiridos (40\%) apontou a opção "outros".

Sobre a apresentação das propostas de projeto a inquirição revelou que as três principais formas de apresentação de projetos utilizadas atualmente são: (1) $87 \%$ dos profissionais declararam que preparam uma planta baixa/ layout em escala; (2) 76\% dos inquiridos dizem que fazem uso de perspectivas, desenvolvidas por algum software específico; e (3) $35 \%$ dos profissionais atestaram que utilizam fotografias junto ao desenho técnico para auxiliar a argumentação da proposta. Verificou-se menor número de profissionais que fazem desenhos à mão livre, sem depender de algum software de projeto cerca de $24 \%$ e $15 \%$ da amostra.

A inquirição investigou, ainda, se há avaliação dos trabalhos desenvolvidos e implantados. A maioria efetiva dos profissionais inquiridos, $71 \%$ dos respondentes, declararam que sempre realizam a etapa de verificação da satisfação do cliente após a implantação e/ou execução do projeto. A opção às 
vezes foi apontada por $12 \%$. Os demais inquiridos relataram que raramente e/ou nunca adotam esta etapa no seu processo metodológico projetual. A inquirição revelou também que $71 \%$ dos inquiridos realizaram esta avaliação através de conversa informal com o cliente, e $16 \%$ dos inquiridos simplesmente aguardam o retorno do cliente para um "novo projeto" como a única forma de verificação dos resultados alcançados com o trabalho.

A partir dessa seção de perguntas com os profissionais, buscou-se verificar se de fato há, entre os inquiridos, algum conhecimento sobre ergonomia e como ocorre sua aplicação. De maneira geral os profissionais apontaram significativo conhecimento do assunto. Verificou-se que mais de $64 \%$ dos inquiridos afirmaram possuir conhecimento sobre os principais pilares da ergonomia física: ambiente fisico da tarefa, antropometria e análise da tarefa. Apenas 2\% afirmaram não possuir nenhum conhecimento sobre o assunto.

Buscou-se identificar em qual (quais) momento(s) do projeto a ergonomia é aplicada, e $41 \%$ dos inquiridos relataram que aplicam os conhecimentos de ergonomia em todas as fases: (1) durante a fase projetação (concepção do projeto); (2) na especificação de equipamentos e/ou mobiliário; (3) durante a fase do programa (elaboração de necessidades); (4) durante a fase de pesquisa conceitual. Mergulhando mais fundo sobre esse assunto, inquiriu-se como "o conhecimento de ergonomia" costuma ser aplicado. O resultado obtido com o questionamento foi: $65 \%$ dos profissionais fazem uso dos conhecimentos de antropometria em seus projetos, e $74 \%$ destes consideram os fatores ambientais. $\mathrm{O}$ fator apontado com destaque pelos profissionais como elemento de ergonomia de maior uso foi análise da tarefa a ser realizada pelo usuário, indicado por $76 \%$ dos profissionais entrevistados. O menor percentual foi apontado por aqueles que fazem uso da ergonomia em seus projetos através das metodologias de análise ergonômica, indicada por $26 \%$ dos profissionais inquiridos.

O último aspecto investigado junto aos profissionais de DI dizia respeito à usabilidade dos projetos. Foi proposta uma reflexão sobre o conceito de usabilidade, e questionou-se se os projetos planejados e implantados possuíam esse atributo ou não na opinião dos inquiridos ${ }^{7}$. Do total de 85 participantes da pesquisa, $51 \%$ foram cautelosos e afirmaram que frequentemente os seus projetos atendem ao conceito de usabilidade da ISO 924111 , e $47 \%$ foram taxativos e asseguraram que sempre seus projetos atendem ao conceito de usabilidade. Apenas $02 \%$ da amostra acreditam que seus projetos às vezes contemplam esse conceito. Importante considerar que a afirmação sobre se o projeto implantado possui ou não usabilidade, conforme a ISO 9241-11, é uma avaliação pessoal e particular do profissional inquirido, sem uso de qualquer instrumento e/ou técnica específica.

\subsection{Considerações sobre o questionário aplicado com os usuários}

Conforme inquirição realizada, as características identificadas revelaram um quadro pictórico do usuário e/ou cliente inquirido: possui entre 48 e 67 anos; metade do sexo feminino e metade do sexo masculino; residem na cidade do Rio de Janeiro, capital. A amostra revelou também que todos possuem nível superior e o estado civil predominante é casado (a), com dois filhos. Estes últimos dados correspondem ao mais recente censo demográfico do IBGE 2010, o qual aponta o número de 50 milhões de lares no Brasil com famílias com estrutura nuclear (casal com filhos), o que representa $49,4 \%$ das famílias brasileiras, demonstrando que de todas as estruturas essa ainda é a dominante ${ }^{8}$. A inquirição apontou que a maioria absoluta dos entrevistados realizou o projeto da

\footnotetext{
${ }^{7}$ Antes de realizar a pergunta, foi apresentado ao inquirido o conceito de usabilidade, conforme a ISO 9241-11, que diz o seguinte: A medida na qual um produto pode ser usado por usuários especificos para alcançar objetivos especificos com eficácia, eficiência e satisfação em um contexto específico de uso. O termo designa o grau de facilidade com que o usuário realiza seus objetivos, sem o auxilio de um ajudante humano, ou seja, quão fácil é usar algo; mecânico, eletrônico ou digital.

${ }^{8}$ Fonte: Censo demográfico IBGE 2010. Disponível em:

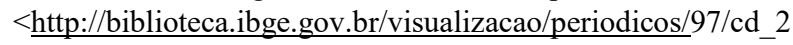
010_familias_domicilios_amostra.pdf. >. Acesso em: 03. dez. $201 \overline{5}$.
} 
residência como um todo. O grau de complexidade evolui à medida que o número de ambientes a ser realizado no projeto aumenta - entende-se como aspecto favorável para a pesquisa.

Constatou-se pelos dados levantados que a investigação sobre as necessidades do usuário para o projeto está sensivelmente dependente de uma entrevista aberta, ou seja, "conversa informal". Para tratar desse assunto, $88 \%$ dos respondentes afirmaram que o profissional utilizou essa técnica. Outros $16 \%$ dos inquiridos declararam que houve uso de conversa e questionário, e $22 \%$ relataram ainda, na mesma pergunta, que o profissional de alguma forma acompanhou a rotina da casa (através da participação em uma das refeições, por exemplo). Deixar o profissional totalmente livre para criar foi a escolha de $34 \%$ do total de usuários investigados.

A inquirição revelou o grau de dificuldade para o usuário expressar suas necessidades: $13 \%$ dos respondentes afirmaram que houve alguma dificuldade, e 19\% dos inquiridos relataram pouca dificuldade. Já $69 \%$ destes disseram que não tiveram nenhuma dificuldade. Neste caso, buscou-se investigar se houve alguma tentativa (por parte do profissional) de saber se ocorreu alguma $a c ̧ a ̃ o$ diferenciada, além das já citadas, para contribuir com uma melhor elucidação das necessidades. Nesta situação, 38\% relataram que não ocorreu nenhuma ação diferenciada e $28 \%$ dos usuários tomaram a atitude (eles próprios) de convidar o profissional para conhecer os hábitos e funcionamento da casa, e outros $19 \%$ fizeram registros fotográficos daquilo que julgaram necessário.

Investigou-se se durante a apresentação da proposta de projeto os comentários e observações dos usuários foram considerados no projeto. Do total de 32 inquiridos, $81 \%$ afirmaram que sim, totalmente; $16 \%$ que sim, parcialmente, e $3 \%$ que sim, contudo prevaleceu a opinião do profissional.

Sobre a apresentação de propostas, verificou-se que a maioria significativa ( $75 \%$ dos usuários) declarou que lhe foi apresentada a proposta de projeto através de desenhos (perspectivas e desenhos técnicos) impressos; para $56 \%$ dos respondentes, foi apresentada proposta através de imagens virtuais, e $31 \%$ dos inquiridos afirmaram que o profissional acompanhou a apresentação realizada em uma loja de móveis planejados. Ainda nesta mesma seção, investigou-se qual a reação do usuário ao ser apresentado a seu projeto de interiores. Verificou-se que a opção mais apontada, por $72 \%$ dos respondentes, indicou que, apesar de satisfeitos, teceram alguns comentários e observações, e 28\% dos respondentes declararam-se satisfeitos com a apresentação da proposta, porém teceram muitos comentários e ajustes.

Sobre a fase de implantação e verificação de satisfação do projeto, foi relatado pelos usuários que a execução e a implantação do projeto foi acompanhada pelo profissional segundo $88 \%$ dos respondentes, enquanto $13 \%$ dos inquiridos relataram que o profissional não acompanhou a implantação do projeto. Ainda sobre esse assunto, 91\% dos inquiridos também revelaram que os profissionais pesquisaram sobre seu grau de satisfação sobre o projeto planejado e implantado, e apenas $9 \%$ afirmaram que não houve investigação sobre sua satisfação no projeto final.

Os usuários apontaram aspectos positivos identificados a partir da relação destes com seus respectivos profissionais de D.I. contratados, durante o planejamento e execução do projeto proposto, e dentre estes destacam-se: profissionalismo, criatividade, conhecimento, flexibilidade, compreensão. Já quanto aos aspectos negativos identificados, 21 usuários declararam que não existem aspectos negativos a relatar, e os demais usuários, representados por 11 inquiridos, teceram críticas ao profissional e seu processo de trabalho. Destacaram-se alguns relatos: "Não houve interesse em saber se estava satisfeito com a reforma, no final meio que sumiu! "; "Informal, sem planejamento"; "Dificuldade em entender a maneira de ser dos clientes"; e "Prazo de execução e algumas falhas quanto a pontos de luz".

Por fim, perguntou-se sobre a hipótese de realizar um novo projeto novamente: o que faria diferente? Há significativa expressividade positiva nos usuários que afirmaram que "não fariam nada de 
diferente, correu tudo bem", representada por $66 \%$ dos respondentes da amostra. Contudo, 19\% destes declararam que "seriam mais detalhistas e exigentes com o projeto". Nesta mesma pergunta um usuário declarou que "participaria mais do processo a fim de prevalecer minha ideia", e outro que "se tivesse oportunidade contrataria outro profissional". É provável que este último comentário tenha sido uma das críticas mais severas feitas por um usuário.

\section{Considerações Finais}

Constatou-se que a habilidade e a experiência do profissional são essenciais para detectar as reais necessidades dos clientes, independentemente do método empregado, assim como verificou-se que atributos técnicos próprios da atividade, aliados a vivência profissional e algumas habilidades pessoais contribuem significativamente para um "feeling apurado" e o uso de melhores estratégias, a fim de propor soluções que atendam às reais necessidades dos clientes.

Os registros das necessidades apontadas pelos usuários, conforme explicitada pelos profissionais inquiridos, alinham-se à etapa proposta nos métodos de projeto em arquitetura e design de interiores, o "programa de necessidades" (demonstradas nas ideias de Silva, 1998; na Norma 13532/95 Elaboração de projetos de edificações - arquitetura, e ainda nas fases apontadas por Gibbs, 2012). Critica-se a ausência de registros sistemáticos nessa etapa do processo, o que contribui para o surgimento de lacunas sobre a execução da ação.

Diante dos dados levantados na seção que trata da etapa inicial para elaboração da proposta, verificouse que a principal (quase única) técnica utilizada é a conversa informal (entrevista aberta) com o objetivo de extrair dos usuários as necessidades para $o$ projeto. Outras técnicas que contribuem para qualificação das informações são realizadas, como a visita técnica com levantamento de medidas no local e registro fotográfico do ambiente. Entende-se que esta etapa é fundamental para o profissional absorver a atmosfera do espaço, o conceito e o estilo do cliente, a fim de propor possíveis soluções. É válido considerar que algumas técnicas costumam ser mais empregadas que outras em função das especificidades de cada projeto e do próprio perfil do cliente.

Sobre o conhecimento e uso de ergonomia e usabilidade acredita-se que, embora os dados apontem elevados índices de conhecimento e uso destas, vale considerar alguns fatos: sabe-se que a formação acadêmica em arquitetura pouco adota esta disciplina entre as cadeiras ofertadas na graduação universitária, e nem todos os cursos de design de interiores no nível tecnólogo dispõem de ergonomia no quadro de disciplinas obrigatórias - e quando possuem a carga horária em geral é mínima. Somente os profissionais com formação em design (independente da habilitação) cursam regularmente a matéria ergonomia com carga horária aceitável. Considerando-se ainda que apenas $33 \%$ dos profissionais afirmaram que investiram em alguma formação complementar, como cursos de especialização (dado identificado na análise do perfil dos inquiridos), dentre outros, isso leva-nos a questionar: qual a origem desse conhecimento relatado pelos profissionais? Será que grande parte dos saberes de ergonomia que os profissionais dizem possuir e utilizar foi adquirido apenas na prática, de forma autodidata? Desta forma, apesar dos dados apontarem elevado conhecimento no assunto, é importante relativizar os resultados.

Percebeu-se, ainda, sensível ausência de sistematização dos processos de ergonomia, os quais os inquiridos afirmam conhecer e empregar, considerando que as assertivas sobre o uso da ergonomia apontadas pelos profissionais, na sua maioria, apresentam origem pautada apenas em técnicas de entrevista aberta, como conversas informais - desde o início do processo, passando pela investigação de necessidades, até a fase de avaliação. Verifica-se também que há ênfase sobre os aspectos de ergonomia apenas na fase inicial do projeto, desprezando-se, na maioria dos casos, a análise da tarefa, a fase de implantação e a validação. Estas observações contribuem para constatar que há fragilidade no discurso e prática dos reais aspectos ergonômicos que permeiam os projetos de interiores. 
Por fim, quando foram inquiridos sobre o atributo de usabilidade os resultados obtidos nesta investigação causam desconforto. Como um projeto desenvolvido por profissional qualificado, onde a premissa da personalização é elevada ao mais alto nível de importância, atrelado a investimentos consideráveis de recursos financeiros e tempo, pode não atender ou atender parcialmente a critérios de usabilidade?

É certo que os resultados dessa investigação, declarados pelos profissionais inquiridos, estão pautados no modo de ver pessoal, subjetivo, de cada inquirido. Considerando-se que $29 \%$ dos profissionais questionados afirmaram que "às vezes, raramente ou nunca" fizeram (ou fazem) avaliação dos projetos realizados e implantados, e quando o fazem utilizam apenas a técnica de entrevista aberta (conversa informal), a satisfação apontada pelos profissionais sobre o aspecto de usabilidade não nos parece factível - pelo menos, como um dado científico. Acredita-se que os fatos apontados pelos profissionais, em grande parte dos casos, tratam apenas de conjecturas a partir de juízo de valor formado por indícios.

Embora expressivo número de usuários tenha declarado não ter tido nenhuma dificuldade em expor suas necessidades, e que, quando houve comentários e/ou ajustes, estes foram prontamente atendidos, a questão não está totalmente elucidada. Afinal, um percentual significativo apontou que existiram aspectos indesejáveis como: inadequada identificação das necessidades do usuário; ausência de verificação sobre a satisfação do usuário; projeto final com falhas de execução; ausência de processo metodológico mais rigoroso; alguma ou pouca dificuldade na compreensão de suas exposições verbais. Estes aspectos reforçam a suspeita de que a técnica entrevista não é suficiente para abarcar o vasto leque de atributos a serem atendidos por um projeto de interiores, e as ações tomadas para resolver as questões indicam que são pequenos escapes ou "remendos metodológicos", que certamente são insuficientes para solução do problema de forma eficiente.

Embora o grau de satisfação seja elevado, principalmente se considerarmos o aspecto da usabilidade do projeto, apontada por unanimidade dos usuários como satisfatória, destaca-se a necessidade de propor melhorias ao processo projetual dos profissionais de D.I., visto que é notória a preocupação em realizar trabalhos de alto nível, gerando clientes satisfeitos e multiplicadores.

A pesquisa revelou elevado nível profissional por parte dos profissionais inquiridos, com espaço para implemento de melhorias. Constatou-se que há necessidade de serem implementadas novas técnicas e ferramentas que complementem o modus faciendi dos profissionais e os conhecimentos de ergonomia que (quando aplicados corretamente) podem contribuir positivamente e significativamente nesse cenário.

Diante dos fatos identificados e relatados, é possível refletir sobre uma nova estrutura metodológica para projeto de interiores. Esta estrutura deverá ser planejada para cada etapa pensando-se na sistematização dos processos com enfoque no usuário, ferramentas metodológicas mais robustas que melhor identificassem as necessidades dos usuários e as adversidades durante a realização do projeto, e ainda com verificação do grau de satisfação do usuário mais precisa. Vale destacar que tal estrutura deverá ser de aplicação prática e com facilidade de adaptação aos variados tipos de projeto de interiores. As sequências deverão ser lógicas e realizadas de acordo com a execução prática do projeto, porém com espaços para revisão caso haja não conformidades pelo caminho.

Considerando-se que a atividade de design de interiores ainda encontra-se numa fase de afirmação e reconhecimento (pelos seus pares e a própria sociedade), acredita-se seguramente que somente através do planejamento e da organização dos processos é possível alcançar níveis elevados de excelência. Em um país que culturalmente observase que mais horas são dedicadas às ações práticas imediatistas, e menos ao planejamento intelectual, reforça-se a importância no investimento dos estudos nas melhorias de métodos e processos eficientes para a atividade de design de interiores, visando cada vez mais a satisfação dos usuários. 
Não restam dúvidas que este é o caminho mais curto para alcançar soluções verdadeiramente satisfatórias em todos os níveis, desde a ideia inicial à execução do projeto, passando pela implantação e os aspectos ergonômicos e de custo. $\mathrm{O}$ caminho a ser perseguido deverá ser sempre o do profissionalismo, através do uso de instrumentos seguros que auxiliem na condução dos trabalhos.

\section{Referências Bibliográficas}

CIPINIUK, A. \& PORTINARI, D. Sobre métodos de Design. In: COELHO, Luiz Antônio (org.). Design Método. Rio de Janeiro: PUC - Rio e Novas ideias, 2006.

COELHO, L. A. (org.) Design Método. Rio de Janeiro: PUC Rio e Novas ideias, 2006.

GIBBS, J. Design de Interiores. Guia útil para estudantes e profissionais. Tradução: Claudia Ardións. São Paulo: Gustavo Gili, 2014. Título original: Interior Design.

HIGGINS, I. Planejar espaços para o design de interiores. Tradução: Alexandre Salvaterra. São Paulo: G. Gilli, 2015. Título original: Spatial strategies for interior design.

IIDA, I. Ergonomia. Projeto e Produção. São Paulo: Blücher, 2005.

LAWSON, B. Como arquitetos e designers pensam. Tradução: Maria Beatriz Medina. 2 ed. São Paulo: Oficina de textos, 2011. Título original: How designers think: the design process demystified.

MARCONI, M. de A.; LAKATOS, E. M. Técnicas de pesquisa. São Paulo: Atlas, 2002.

MORAES, A. de (org.) Ergodesign do ambiente construído e habitado. Rio de Janeiro: iUsEr, 2004.

MORAES, A. de.; MONT'ALVÃO, C. Ergonomia: conceitos e aplicações. $4^{\mathrm{a}}$ ed., Rio de Janeiro: $2 \mathrm{AB}$, 2012.
Norma ABNT NBR ISO 9241-11 - Orientações sobre usabilidade. Fonte:

$<\underline{\text { http://www.abntcatalogo.com.br/norma.aspx? ID }=8}$ $\underline{6090}>$. Acesso em: 16. mar. 2016

Norma ABNT NBR 13532/95 - Elaboração de projetos de edificações - Arquitetura. Fonte: < https://pt.slideshare.net/LucianoOtavio/nbr-13532elaborao-de-projetos-de-edificaes-arquitetura1995> Acesso em: 10. abril. 2016.

SILVA, E. Uma introdução ao projeto arquitetônico. Porto Alegre: UFRGS, 1998.

\section{Agradecimentos}

Ao Laboratório de Ergonomia e UsabilidadeLEUI da Pontifícia Universidade Católica do Rio de Janeiro - PUC - Rio e à Fundação de Amparo à Pesquisa e ao Desenvolvimento Científico e Tecnológico do Maranhão - FAPEMA. 